the proteins have a widely varied but positive interaction with the RNA, with no sharp distinction between "binding" and "non-binding" proteins; the very existence of the controversy over the specificity of $\mathrm{S} 17$ and $\mathrm{S} 13$ binding supports this view.

\section{Organic pollutants in the sea}

\section{from a Correspondent}

THE requirements of industry and of agricultural practice have in recent years greatly enlarged the search for and use of a variety of classes of organic compounds which in large quantities eventually reach the sea. The nature, origin, dispersal persistence and fate of some of the more commonly occurring pollutants including halogenated hydrocarbons, organic heavy metal compounds and crude oils were reviewed at a discussion meeting organised by the Royal Society on July 4-5.

N. S. Thom and A. R. Agg (Water Research Centre, Stevenage) cited more than 200 substances believed to be significant pollutants of water in the United Kingdom, and C. R. Pearson and G. D. McConnell (ICI Ltd, Brixham and Runcorn) reviewed a range of industrial hydrocarbons in widespread use. It seemed from the papers of $\mathrm{E}$. D. Goldberg (Scripps Institution, La Jolla) and J. E. Portmann (Fisheries Laboratory, Burnham-on-Crouch) that although the input of both DDT and dieldrin into the oceans of the northern hemisphere may have passed its peak, the output is increasing in the equatorial regions and southern hemisphere and world production of organochlorine pesticides is increasing. Although, as Pearson and McConnell pointed out, the many kinds of chlorinated hydrocarbons denived from $\mathrm{C}_{1}$ and $\mathrm{C}_{2}$ hydrocarbons used as intermediates in further manufacture or as solvents and carriers are not unexpectedly dispersed to the sea substantially through the atmosphere, heavier synthetic halogenated hydrocarbons such as PCBs and DDT residues may similarly be transported as gas molecules or adsorbed on airborne dust. Goldberg and Portmann each suggested a $25 \%$ transference to the oceans by these means.

Within the sea persistence of organic pollutants varies greatly according to their chemical stability, susceptibility to biodegradation and the routes and terminal situations of their passage. Half lives varying from a few hours (for example, $\mathrm{CCl}_{4}$ ) to days or weeks (EDC tars deriving from vinyl chloride production) to years (for example, PCBs, DDT, aromatic compounds of high carbon number) were cited by $\mathbf{S}$. Jen- sen (Wallenberg Laboratory, Stockholm), R. Lange (Odense University) and E. D. S. Corner (Marine Biological Association, Plymouth) among other speakers as examples of varying persistence.

G. Eglinton (University of Bristol) showed a film demonstrating a newly developed computerised gas chromatography-mass spectrometry system used for the determination and assay of pollutants in coastal muds, a system which may prove to be useful also in determining the natural occurrence of organic compounds in muds deposited in pre-industrial times.

The uptake of organic pollutants by marine organisms and their levels of occurence and sites of accumulation were discussed by several speakers. Their differential absorption by lipids was stressed and Portmann made the point that although many measurements had been made of the concentrations of the more persistent compounds in a variety of organisms of the higher trophic levels, little was known of transfers at lower trophic levels, for example in the grazing of phytoplankton by zooplanktants. Corner gave an account of work in progress on the utilisation, tranformation and breakdown of fossil fuel hydrocarbons by marine crustaceans, a subject of particular interest in studies of the effects of oil spills. D. E. Hughes and P. McKenzie (University College, Cardiff) reported laboratory and field experiments indicating that about $40-90 \%$ of oil may be degraded by microbial attack; alkanes and other saturated compounds are more readily degraded than aromatic and heterocyclic compounds. A. J. Van Benekom (Netherlands Institute for Sea Research, Texel) reported on some consequences of discharges from the Rhine on the chemistry and plankton production of coastal water of the Southern Bight of the North Sea. Diatom growth was at times inhibited and the general level of production was unusually low and subject to irregular peaks. Blooms of Phaeocystis and possibly other toxic flagellates seemed to be favoured by these conditions.

\section{New model of lunar interior}

\section{from Peter.J. Smith}

According to Toksöz et al. (Science, $176,1012 ; 1972)$, the Moon has a $50-$ $60 \mathrm{~km}$ thick crust in the eastern part of Oceanus Procellarum; and Nakamura et al. (Science, 181, 49; 1973) concluded that the deep lunar interior below a depth of about $1,000 \mathrm{~km}$ is probably partially molten. But what is the state of the Moon between these two extremes, in the mantle which accounts for the major part of the lunar volume? The complete answer to this question is not yet available, although Nakamura et al. (Geophys. Res. Lett., 1, 137; 1974) have now moved some way towards it in reporting new seismic data from the four Apollo seismic stations still in operation.

Nakamura and his colleagues have attempted to determine both $\mathbf{P}$ and $\mathbf{S}$ wave velocities throughout the lunar mantle from large meteoroid impacts, high frequency teleseismic events and deep moonquakes. The observed $P$ wave velocity shows a systematic variation with epicentral distance, indicating that the subcrustal region cannot have a constant velocity. For example, $P$ wave arrival times at distances greater than $70^{\circ}$ are delayed by $10 \mathrm{~s}$ with respect to those expected from data at shorter ranges-an offset which could arise from a negative velocity gradient in the upper few hundred kilometres of the mantle, from a small stepwise decrease in velocity at a depth of the few hundred kilometres, or from a combination of the two.

For a negative velocity gradient, the travel-time curve would be continuous between $50^{\circ}$ and $70^{\circ}$; and on this assumption, Nakamura et al calculate that the $\mathrm{P}$ wave velocity would decrease from about $8.1 \mathrm{~km} \mathrm{~s}^{-1}$ at the top of the mantle to about $7.8 \mathrm{~km} \mathrm{~s}^{-1}$ at a depth of about $500 \mathrm{~km}$, followed by a slight increase. For a stepwise decrease, the travel-time curve would be discontinuous with a shadow zone somewhere between $50^{\circ}$ and $70^{\circ}$; and calculations put the minimum depth of the step at $200-300 \mathrm{~km}$ and its velocity contrast at $0.3 \mathrm{~km} \mathrm{~s}^{-1}$. For a combination situation, the velocity gradient and velocity contrast would be smaller than those I have given. Unfortunately, the available data are too uncertain to enable a decision to be made about which of the three cases actually obtains, although Nakamura and his colleagues seem to favour the combination.

More certain (though based on a single data point) is a very large delay in $\mathrm{P}$ wave arrival at $168^{\circ}$ which, if subsequently confirmed, would suggest that the Moon has a low velocity core. The present data put a limit of 170 $360 \mathrm{~km}$ on the radius of such a core and a limit of $3.7-5.1 \mathrm{~km} \mathrm{~s}^{-1}$ on its $P$ wave velocity. Also conspicuous is the near linearity of the $S$ wave traveltime curve beyond distances of $90^{\circ}$, indicating a large, and apparently increasing, delay of $\mathbf{S}$ wave arrivals relative to $P$ wave arrivals at greater distances. Possible explanations involve one or more of the following effects: refraction of waves by a large negative velocity gradient at about $300 \mathrm{~km}$ depth, diffraction of waves around a discontinuity at this depth, or penetration of 